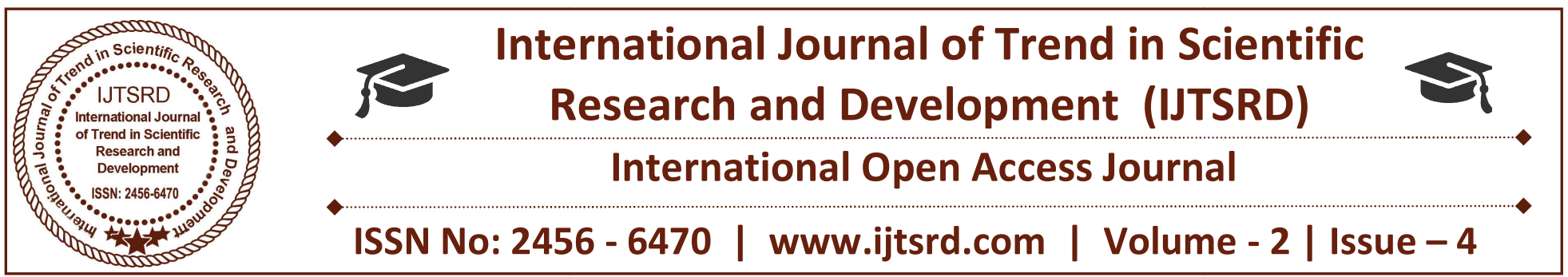

\title{
Enclosure Design for 3D Printing
}

\author{
Harshna Gupta ${ }^{1}$, Gaurav Chaudhary ${ }^{2}$, Krishna Mohan Singh ${ }^{3}$, Devendra Kumar ${ }^{4}$, Ashish Malik \\ ${ }_{1,2,3,4}$ B. Tech Student, ${ }^{5}$ Faculty \\ 1,2,3,4,5 Department of Mechanical Engineering, \\ 1,2,3,4,5 ABES Engineering College, Ghaziabad, Uttar Pradesh, India
}

\begin{abstract}
In the recent past many industries have widely started adopting $3 D$ Printing for prototyping and manufacturing of low volume customized parts. This paper will look at additive manufacturing or 3D printing and how electronic enclosures can be developed using this technology. It will define the meaning of this term and what is so significant about it. It will delve a bit into its advantages, compared to conventional methods of manufacturing and its types. Then finally we will discuss the steps involved in design of these enclosures and some guidelines while designing them for $3 D$ printing.
\end{abstract}

Keywords-- Prototype, $3 D$ printing, CAD, CMM

\section{INTRODUCTION TO ADDITIVE MANUFACTURING}

3D printing, additionally referred to as additive manufacturing, is a process by which $3 \mathrm{D}$ solid parts of any shape or configuration can be created from a digital file. The creation is obtained by setting down layers of a specific material until the entire object is created. Each of these layers represents a thinly sliced horizontal cross-section (similar to the output of an ordinary printer, this is why it is called printing) of the eventual object, in contrast to traditional subtractive manufacturing methods which relies upon the removal of material to create something. [2]

Siddharth Bhandari in his research quotes "is regarded that Hideo Kodama of Nayoga Municipal Industrial Research Institute printed the first solid object from a digital design. However, the credit for the first 3D printer goes to Charles Hull, who in 1984 designed it while working for the company he founded, 3D Systems Corp. Charles Hull was the pioneer of the solid imaging process known as stereolithography. The STL (stereolithographic) file format which is still the most widely used format used today in 3D printing was also founded by him. He gave birth to rapid prototyping along with development of $3 \mathrm{D}$ printing. He initially used photopolymers heated by ultraviolet light to achieve the melting and solidification effect." [3]

\section{3D PRINTING PRINCIPLES}

3D printing works mainly on the principle of stereolithography. In a patent in 1984 Charles Hull stated it as "a system for generating three-dimensional objects by making a cross-sectional pattern of the object to be formed. This implies that any $3 \mathrm{D}$ object developed using a 3D drawing software, is first divided into layers. The layers are then printed one by one by the machine on top of one another. First step of $3 \mathrm{D}$ printing is the generation of a 3D printable model. This model is generated using a CAD software. Then the STL file is generated by running the design through a converting software. Such software allows designers to customize various aspects of the design such as temperature, layer thickness, and outer finish, etc. After generating the STL file the part is ready to be printed. The converted STL file is fed into the printer and according to the layers we have obtained, the machine starts laying the plastic out layer by layer". Not only plastic but anything ranging from liquid, powder, paper or sheet material. The layers are automatically fused to get the final shape

The object may take anywhere from several minutes to several hours to complete, depending on the size and complexity of the model and also on the type of machine used. Some additive manufacturing techniques are capable of using multiple materials to 
construct parts. They can also use multiple colour combinations simultaneously.

\section{ADVANTAGES OF 3D PRINTING}

Parts are created in 3D printing by building up objects layer by layer. This method has many advantages over traditional manufacturing techniques, i.e. material removal techniques. 3D printing may not replace many traditional manufacturing methods as yet but there are many applications where a $3 \mathrm{D}$ printer is able to deliver a design quickly, with high accuracy from a functional material. If designers understand the advantages of $3 \mathrm{D}$ printing, they are able to make better decisions when selecting a manufacturing process and deliver better products. The various advantages are as follows:

\section{A. Speed}

Additive manufacturing wins over other processes because of the speed at which parts can be produced compared to traditional methods. Complex designs can be uploaded in form of a CAD model and printed in a few hours. Due to this the design can be rapidly verified and new ideas can be developed. Earlier it would have taken days or even months for a designer to develop a prototype, with additive manufacturing it can be available with the designer within a few hours.

\section{B. Single step manufacture}

It is important for a designer to produce a product as efficiently as possible. By using traditional material technologies, most parts require a large number of steps. This large number of steps affect the quality and manufacturability of the products. Additive manufacturing machines complete the product in one step without any involvement of the operator. After finalising the CAD model, this could be fed to the $3 \mathrm{D}$ printer, and printed in a single step in a few hours. The ability to produce a part in one step reduces the dependence on different manufacturing processes (machining, welding, finishing etc.) and gives the designer greater freedom to develop the final product.

\section{Risk mitigation}

If a faulty prototype is made it costs both in time and money. A huge financial loss can occur even when a small change is made in the mould and fabrication. Thus, the risk of loss in prototyping in investing in expensive manufacturing equipment like jigs and fixtures is eliminated by the ability to print and verify a production ready prototype. This helps to build confidence to one's design, before making huge investments required for the mass production

\section{Complexity and design freedom}

Traditional manufacturing processes imposed many restrictions on manufacturability which are done away with in additive manufacturing. It constructs components layer by layer, so the design requirements such as undercuts, draft angles and tool access do not hinder when designing parts to be $3 \mathrm{D}$ printed, However the minimum size of the details that can be accurately printed is restricted, most of the limitations of additive manufacturing are about how to optimally orientate a print to reduce support dependency and the likelihood of print failure. This gives designers a large amount of freedom and enables him to easily create very complex geometries.

\section{E. Sustainability}

Material removal manufacturing methods, such as CNC milling, remove a large amount of material from the initial block, which results in high volumes of waste material. Additive manufacturing methods however, only use the material required to build a part. Most of the processes even use materials which can be recycled and be used for producing multiple parts. Consequently, additive manufacturing process produces very little waste.

\section{F. Types of 3D printing technologies}

3D printing or Additive Manufacturing is an umbrella term that encompasses multiple processes. Every 3D printing process has its benefits and limitations and each is more suitable for certain applications than others. The choice of technology depends on the following factors:

1. The required material is already known

2. The characteristics of the end part (physical or visual) are already defined

3. Certain process capabilities (accuracy, build size etc) are required

Various 3D printing technologies are:

1. Stereolithography(SLA)

2. Digital Light Processing(DLP)

3. Fused deposition modeling (FDM)

4. Selective Laser Sintering (SLS)

5. Selective laser melting (SLM)

6. Electronic Beam Melting (EBM)

7. Laminated object manufacturing (LOM) 


\section{ENCLOSURE DESIGN FOR 3D PRINTING}

While the power of a hardware product comes from its internal components, a product is typically recognized by its enclosure, the outer shell that encloses electronic products, making them appealing and user-friendly. This might be a simple container to keep small items organized or a fully functional prototype to show stakeholders. With CAD software and a desktop 3D printer, one can create a custom snap fit enclosure in following steps.

\section{Step 1. Deciding about product requirements}

With any design, the best thing is to begin by thinking about requirements, which helps in keeping the development in scope and avoiding adding cost and complexity where it is not needed. At this stage, the designer should know, what does the enclosure need to do and what are its most basic functions. The requirements should not go on to include more specific design decisions such as wall thickness dimensions at this point. In the beginning, the requirements should be as streamlined as possible so as to have flexibility in design later on.

\section{Step 2. Finalising product dimensions}

Using digital callipers or some CMM to measure the electronic component. The best way to start enclosure design is by accurately reverse-engineering the PCB, measuring the board size, the location of mounting holes, and any ports or plugs that will need to be accessed through the enclosure. Rather than to simply measure the overall maximum dimensions as a box, it's essential to know exactly where the main features are so that they can be accommodated. In Solidworks, it is possible to reproduce these measurements as a grouping of basic boxes in a single part file.

\section{Step 3. Designing the bottom enclosure}

In Solidworks, the enclosure is best designed as an assembly, with each half of the enclosure modelled as a separate part. Starting with the base half of the enclosure as a new part, the first important decision is to determine how much of a tolerance to have between the perimeter of the PCB and the enclosure. SLA and SLS 3D printers are highly accurate, so the designer can tighten the tolerance to $0.5 \mathrm{~mm}$ without much risk. An FDM printer may warp the design and lift it off of the print plate, so a designer should allow a larger tolerance of $1.5-2 \mathrm{~mm}$ to ensure that the PCB will still fit inside even if the walls are somewhat distorted.

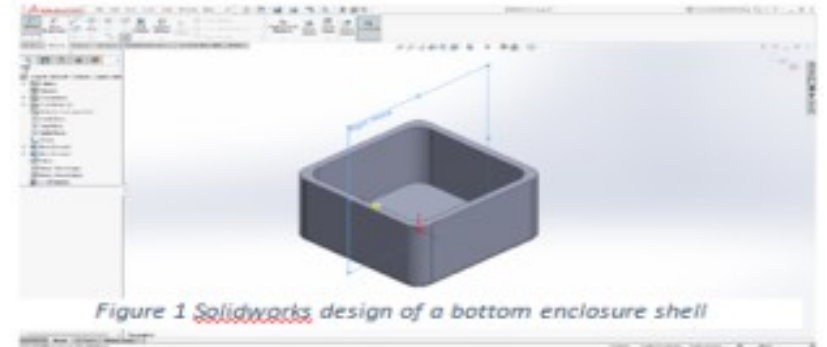

Figure 1: Solidworks design of a bottom enclosure shell

\section{Step 4: Modelling the internal components}

Now on to the enclosure one should start a design by thinking about how the innards will be held. Ideally, the designers have a good idea of what's going inside the enclosure so they can accurately design around it. To do this accurately, the designer should find some sort of dimensional drawing from the PCB manufacturer, if not an actual 3D model called the placeholder model. Placeholder models don't need to reflect every feature of the part. The outer dimensions and any mating features are important to model, but everything else can be left out.

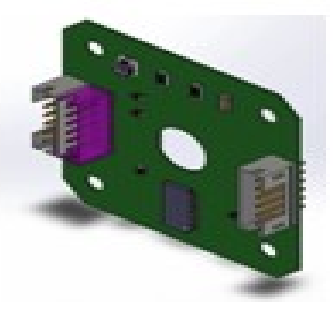

Figure 2: Placeholder model of a PCB

\section{Step 4: Adding slots and external holes}

The next step is to start cutting away the openings for the ports. One common mistake is only cutting away just enough material to expose the port connection, be it a USB or HDMI, without taking into account that many cables around the male connector can be quite bulky and need to reach into the enclosure to connect to the port (especially if the port is set in from the edge of the PCB, farther away from the enclosure). So it's best to be generous with the port openings. An extra $2 \mathrm{~mm}$ all the way around is a good starting point. Some of the cuts reach the top and some of the ports on the board stick out beyond the edge of the PCB, so in order to fit the PCB, it is needed to allow room for them to slide down. some of these will be closed off with the top enclosure part, but one could choose to create a larger bottom enclosure so that the entire PCB and ports fit inside. 


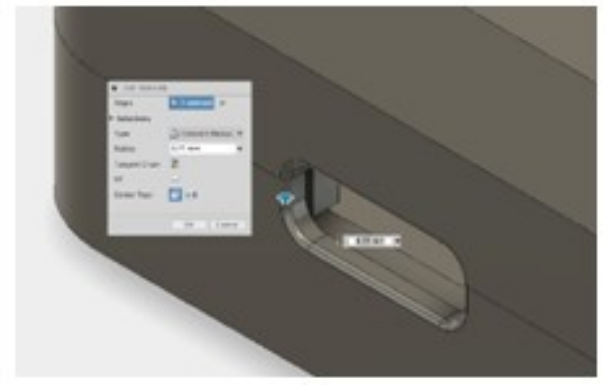

Figure 3: A USB slot

\section{Step 5. Creating support ribs and bosses}

Without increasing the wall thickness, adding ribs enhances product strength and rigidity, in order to save the amount of plastic to reduce weight and lower cost, overcome deformation caused by uneven thickness, to facilitate the flow of plastic melt, especially for thin wall place. The mounting bosses are designed to hold the PCB in place with the help of screws or spacers.

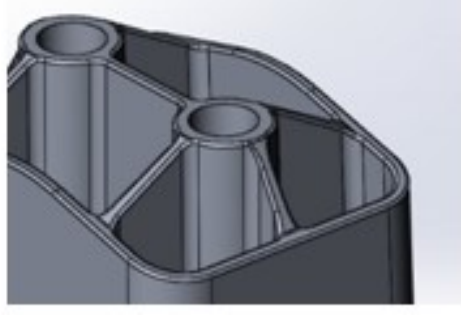

Figure 4: Mounting bosses and ribs

\section{Step 6. Designing the top enclosure}

Now that the bottom enclosure is completed, the top section is easy. The top enclosure is given the same treatment of cut details to accommodate some of the taller ports, as well as the addition of material to close off some of the gaps left by the bottom enclosure.

\section{Step 7. Securing enclosure assemblies}

Some alternatives for securing 3D printed enclosures are snap fits, interlocking joints, threaded fasteners and living hinges. Installing snap-fits and push-fits for an enclosure that does not require repeated opening is much easier because the joint does not have to be as wear-resistant. For quick prototypes adhesives are a fast and simples method to permanently secure the enclosure. 


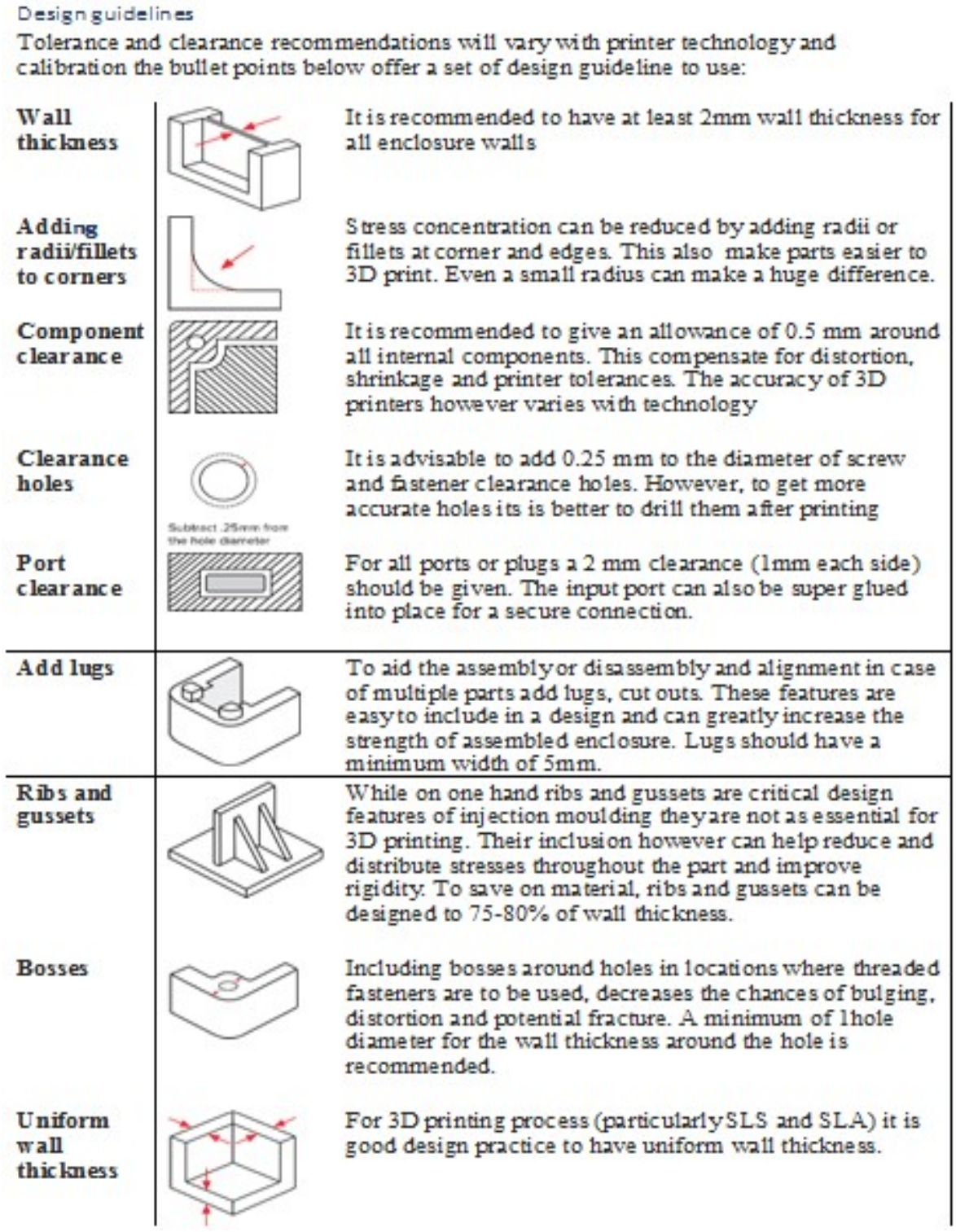

\section{3D PRINTING ENCLOSURE TECHNOLOGIES}

3D printing can be done by various technologies. Also the range of enclosure applications is vast. The table below discusses how these technologies are suitable for various applications.. 


\begin{tabular}{|c|c|c|}
\hline Application & Description & Printing Technology \\
\hline $\begin{array}{l}\text { Rapid } \\
\text { prototyping }\end{array}$ & $\begin{array}{l}\text { Prototyping plastics products is a cost effective } \\
\text { and quick method of printing enclosures after } \\
\text { designing and before mass production. }\end{array}$ & $\begin{array}{l}\text { Fused Deposition } \\
\text { Modelling }\end{array}$ \\
\hline $\begin{array}{l}\text { High } \\
\text { Temperature }\end{array}$ & $\begin{array}{l}\text { Generally, heat resistant plastics are designed to } \\
\text { remain stable up to temperatures as high as } \\
80 \square\end{array}$ & Material Jetting \\
\hline $\begin{array}{l}\text { High quality } \\
\text { surface } \\
\text { finish }\end{array}$ & $\begin{array}{l}\text { Cost and time are the two deciding factors for } \\
\text { the surface finish. SLS nylon results in a satin- } \\
\text { like matte finish that is slightly grainy to the } \\
\text { touch while Material Jetting and SLA offer fine- } \\
\text { detail models with very smooth surfaces. }\end{array}$ & $\begin{array}{l}\text { Stereolithography } \\
\text { apparatus or Material } \\
\text { Jetting }\end{array}$ \\
\hline $\begin{array}{l}\text { High } \\
\text { accuracy }\end{array}$ & $\begin{array}{l}\text { SLS nylon, SLA and Material Jetting printed } \\
\text { parts are highly accurate and are capable of } \\
\text { printing to within } 0.2-0.5 \mathrm{~mm} \text {. They give an } \\
\text { excellent surface finish. SLS nylon does not } \\
\text { require any support while the support used for } \\
\text { material jetting is typically dissolvable and easy } \\
\text { to remove resulting in an smooth surface after } \\
\text { post processing. }\end{array}$ & $\begin{array}{l}\text { Stereolithography } \\
\text { apparatus, Selective } \\
\text { laser } \\
\text { sintering or Material } \\
\text { Jetting }\end{array}$ \\
\hline Transparent & $\begin{array}{l}\text { Transparency makes inspection or verification } \\
\text { of internal parts easier }\end{array}$ & $\begin{array}{l}\text { SLA or material } \\
\text { jetting }\end{array}$ \\
\hline
\end{tabular}

\section{CONCLUSION}

Industrial adoption of 3D Printing has been increasing gradually from prototyping to manufacturing of low volume customized parts. Creating optimal enclosure designs that reflect your requirements and intent can be challenging at the best of times, let alone when it's unchartered territory. That's why, various prototypes are required to be created while developing an electronic enclosure. 3D printing solves this problem at best keeping in mind above mentioned considerations.

\section{References}

[1] 3d printing technologies in various applications, Ramya, International journal of mechanical engineering and technology (IJMET)volume 7, issue 3, May-June 2016,

[2] 3d printing and its applications Siddharth

Bhandari, Regina,,International journal of

computer science and information technology

research, vol. 2, issue 2, pp: (378-380), month:

April-June 2014,

[3] https://www.3dhubs.com/knowledge-

base/enclosure-design-3d-printing-step-step-guide

[4] https://www.protocase.com/blog/2017/02/16/elect

ronic-enclosure-design-101/
[5] https://www.fictiv.com/hwg/design/enclosuredesign-101 